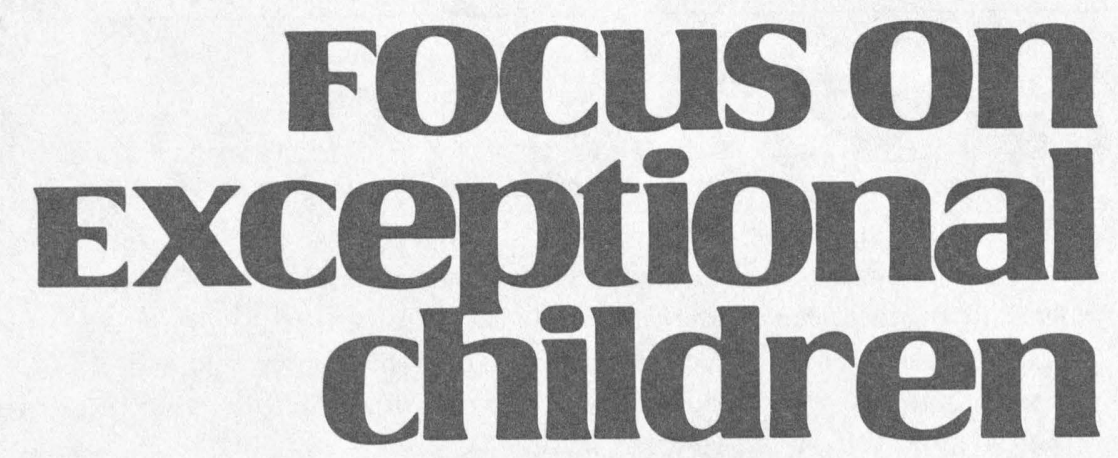

\title{
Developing Math Automaticity in Learning Handicapped Children: The Role of Computerized Drill and Practice
}

\author{
Ted S. Hasselbring, Laura I. Goin, and John D. Bransford
}

Educators generally have agreed that the solution to developing automatic recall of math facts in children is through the use of considerable amounts of drill and practice (Ashcraft, 1985; Gagne, 1983). Recently, many educators have discovered that one means of delivering large amounts of drill and practice in a motivating and carefully monitored environment is through a computer. Thus, it follows that computers logically would be ideal for developing automaticity in learning handicapped children. Indeed, we have found that computer-based drill and practice can be used to develop automaticity, but only when specific prerequisite conditions are met. If these prerequisite conditions are not met, our research, as well as the research of others (Howell \& Graica, 1985; Rieth, 1985), has shown that computer-based drill and practice results in little or no improvement on the part of handicapped students.

\section{THE IMPORTANCE OF AUTOMATICITY IN MATHEMATICS}

Many teachers and parents are content when learning handicapped children can compute answers to basic math facts by using counting strategies (e.g., fingers and number lines) or electronic calculators. But recent research suggests that these procedures can interfere with learning higher level math skills such as multiple-digit addition and subtraction, long division, and fractions (Resnick, 1983). Most cognitive scientists today believe that as basic skills become more highly practiced, their execution requires less cognitive processing capacity, or attention, and they become automatic. All people have a limited capacity for information processing. If they do not have to use part of this limited capacity for performing basic skills, they have more capacity remaining for understanding higherorder concepts. Thus, the ability to succeed in higher-order skills appears to be directly related to the efficiency at which lower-order processes are executed.

Authors Hasselbring, Goin, and Bransford are all affiliated with the Learning Technology Center, Peabody College of Vanderbilt University. 
Research by Lesgold (1983) and Torgesen (1984) supports the idea that automaticity in basic skills is a necessary prerequisite to success in reading and math. They suggest that learning handicapped children do poorly in reading and math because they may have failed to master the component processes required to understand text and to solve math problems. An example can be drawn from reading. Consider a child who cannot recognize words by sight. As he or she reads along, excessive attention resources must be devoted to the task of word recognition by sounding out each word. This process leaves fewer mental resources available for higherorder skills such as thinking about the meaning of the materials being read. Thus, by the time the student reaches the end of the passage, he or she remembers or comprehends very little.

Processing problems similar to those encountered in reading can also occur in math. If the student is constantly having to compute the answers to simple addition and subtraction facts, part of the student's thinking capacity is reduced and less is left for interrelating higher-order concepts that the student has to learn. For example, a child who is performing a long division problem must monitor constantly

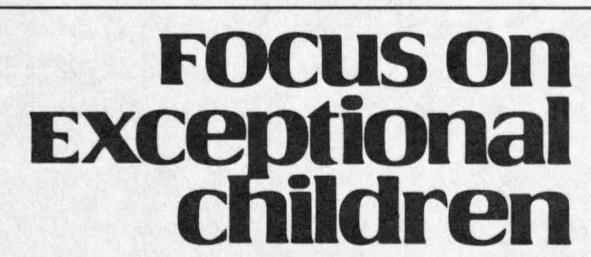

FOCUS ON EXCEPTIONAL CHILDREN (ISSN0015-511X) (USPS 203-360) is published monthly except June, July, and August as a service to teachers, special educators, curriculum specialists, administrators, and those concerned with the special education of exceptional children. This publication is annotated and indexed by the ERIC Clearinghouse on Handicapped and Gifted Children for publication in the monthly Current Index to Journals in Education (CIJE) and the quarterly index, Exceptional Child Education Resources (ECER). It is also available in microform from Xerox University Microfilm, Ann Arbor, MI. Subscription rates: Individuals, \$24 per year; institutions, \$30 per year. Copyright (c) 1988, Love Publishing Company. All rights reserved. Reporduction in whole or part without written permission is prohibited. Printed in the United States of America. Second class postage is paid at Denver, Colorado.

POSTMASTER: Send address changes to: Love Publishing Company

Executive and Editorial Office

1777 South Bellaire Street

Denver, Colorado 80222

Telephone (303) 757-2579

EDITORIAL BOARD

Edward L. Meyen

University of Kansas

Glenn A. Vergason Georgia State University

Richard J. Whelan

University of Kansas Medical Center

Stanley F. Love

Publisher
Carolyn Acheson

Senior Editor where he or she is in that procedure, requiring a certain amount of attention resources. If the child must use counting strategies to subtract or multiply during the division process, these procedures also must be monitored. This draws upon the limited attention resources, and the student often fails to grasp the concepts involved in multiple-digit division.

Based on the research findings cited above, we contend that, for most learning handicapped children, more emphasis should be placed on developing rapid, effortless, and errorless recall of basic math facts. The problem to date, however, is that existing methods have been unsuccessful in moving these students from the use of counting strategies to automatic retrieval of basic facts.

\section{MATHEMATICAL KNOWLEDGE}

Mathematical knowledge of basic facts can be classified as one of two types. The first type, called declarative knowledge, can be conceptualized as an interrelated network of relationships containing basic problems and their answers, such as $4+7=11$ or $11-4=7$. The facts stored in this network have different strengths that determine how long it takes to retrieve an answer. The stronger the relationship, the more rapid and effortless is the retrieval process. For example, if the fact $2+3=5$ has greater associative strength than the fact $7+5=12$, it will take less time to retrieve the answer 5 to the first of these two problems (Pellegrino \& Goldman, 1987).

Ideally, facts stored in this network are retrieved from memory quickly, effortlessly, and without error. As we shall see, however, this is often not the case with learning handicapped children. Most learning handicapped children have not established a declarative knowledge network, and instead of retrieving facts from memory, they rely on a second type of mathematical knowledge, called procedural knowledge.

Procedural knowledge refers to methods that can be used to derive answers for problems lacking pre-stored answers. For example, in the problem $6+8$, a student might use a common counting strategy in which the larger of the two addends (8) is stated and the student increments the smaller addend on his or her fingers while saying $9,10,11,12$, 13, 14. Although correct answers can be obtained using procedural knowledge, these procedures are effortful and slow, and they appear to interfere with learning and understanding higher-order concepts.

\section{NORMAL DEVELOPMENT OF AUTOMATICITY}

At any point in time from preschool through at least the fourth grade, most nonhandicapped children will have some facts that they can retrieve from memory automatically and some that have to be reconstructed using procedural knowledge. From the fourth grade through adulthood, simple ad- 
dition and subtraction problems are solved via retrieval with a continued strengthening of relationships between problems and answers, which results in further increases in the speed of retrieving all facts (Ashcraft, 1985).

In contrast to their nonhandicapped peers, learning handicapped children have a serious problem with respect to the retrieval of elementary number facts. Fleischner, Garnett, and Shepard (1982), as well as Russell and Ginsburg (1984), have found that learning handicapped children are substantially less proficient than their nonhandicapped peers in retrieving the answers to basic math facts in addition and subtraction. Our own research confirms this finding (Hasselbring, Goin, \& Bransford, in preparation). In a recent study where we compared age-matched learning handicapped and nonhandicapped children's ability to recall basic addition facts from memory, we found several differences between the two groups.

As shown in Figure 1, by age 7, nonhandicapped students can recall more facts from memory than their learning handicapped peers can. Further, this discrepancy increases as age increases. Thus, as learning handicapped children get older, they fall further and further behind their nonhandicapped peers in the ability to recall facts from memory.

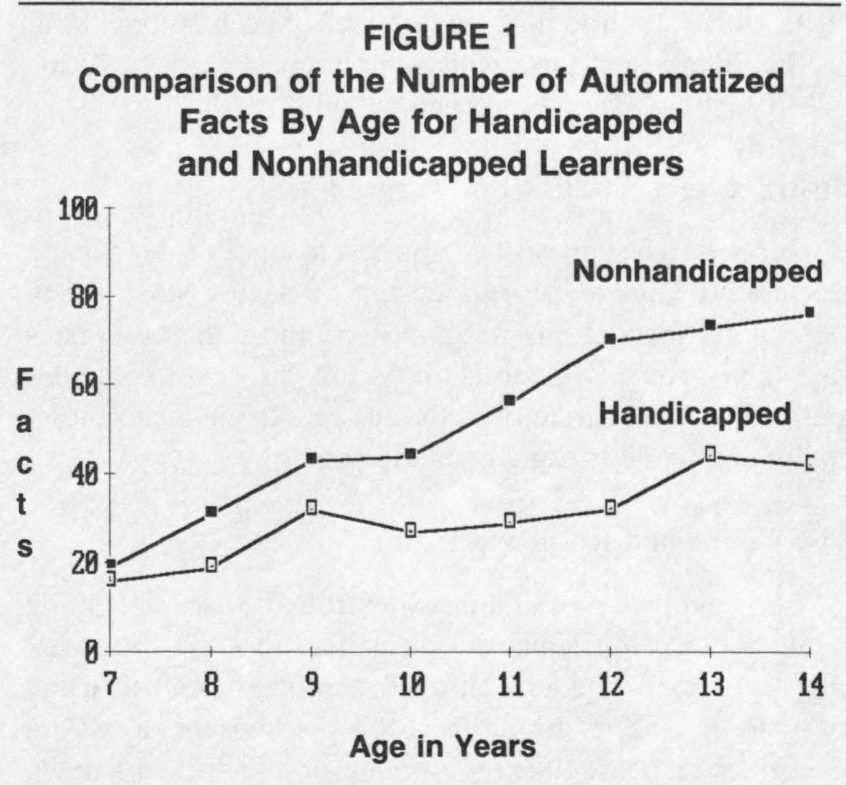

Also, a discrepancy exists between the two groups in their accuracy of responding. As shown in Figure 2, the accuracy of responding is approximately $20 \%$ lower for younger learning handicapped children, ages 7 and 8 , than for their nonhandicapped peers. By age 9 , however, the discrepancy is reduced to about $5 \%$ between handicapped learners and their nonhandicapped peers. This level is maintained to at least age 14 .

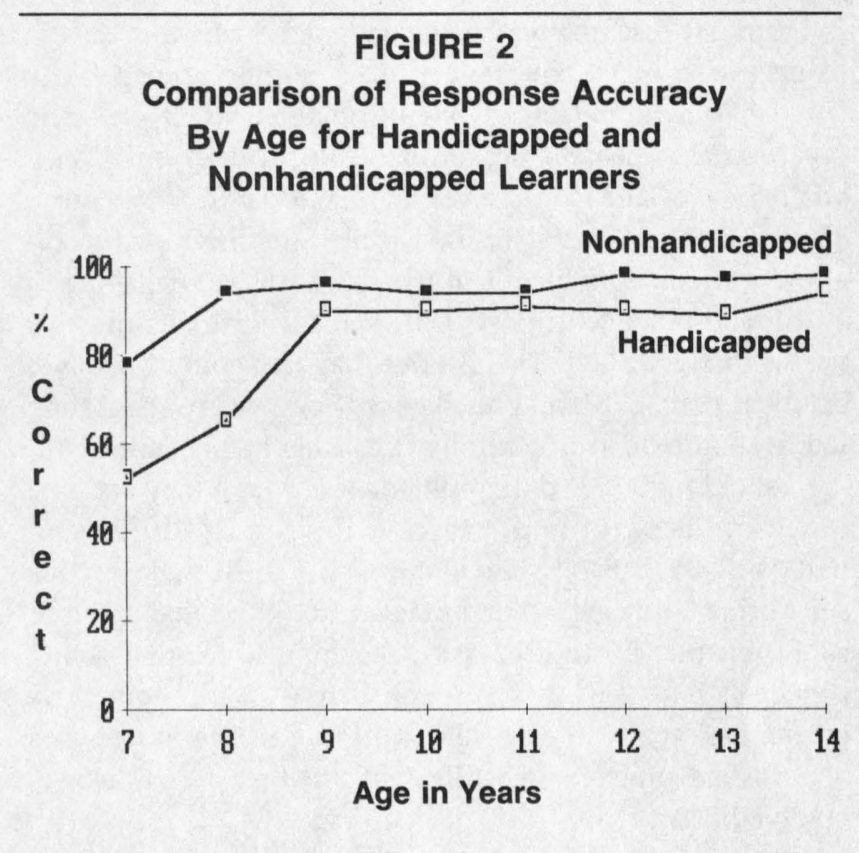

These findings suggest that once learning handicapped children find a strategy that is successful (usually counting), they do not continue a normal developmental progression and shift to a more efficient strategy, such as retrieving answers from memory, as do their nonhandicapped peers. Although there is little information about any particular difficulties that learning handicapped children experience in the retrieval of this information, the evidence that does exist suggests that these children do not suffer from a conceptual deficit (Russell \& Ginsburg, 1984); rather, attachment to one successful strategy causes the disruption to normal development. What this suggests is that with appropriate and sufficient amounts of instruction, learning handicapped children can develop automaticity in basic math facts.

\section{EFFECTIVENESS OF COMPUTER-BASED DRILL AND PRACTICE}

In a recent study examing the effect of arcade-type drill and practice software on the automatization of addition facts, we found that this form of drill and practice had no effect on developing automaticity in learning handicapped youngsters unless they had established declarative knowledge networks between problems and answers before engaging in the drill and practice. Even after as many as 70 sessions on the computer, children who came to the activity using counting strategies to solve basic facts left the activity using the same counting strategies. On the other hand, if a student came to the drill and practice activity able to recall facts from memory, albeit slowly, as few as 20 sessions on the computer often led to automatic retrieval of those facts. 
From our research we have concluded that if a student is using procedural knowledge (i.e., counting strategies) to solve basic math facts, typical computer-based drill and practice activities do not produce a developmental shift whereby the student retrieves the answers from memory. Thus, we believe that if a child has not established an association between a problem and its answer before engaging in a drill and practice activity, time spent in drill and practice is essentially wasted. This is not to say that computer-based drill and practice should not be used, but we are suggesting that it should be used carefully. Learning handicapped children should practice only problems for which they are able to retrieve answers from memory. Hofmeister (1983) supports our conclusions about the use of drill and practice software, stating, "Drill and practice activities that are used as a substitute for the necessary teaching of the underlying concepts, and drill and practice that is not followed by meaningful applications of the skills, are inappropriate uses of drill and practice, regardless of whether a computer is involved or not (p. 4-2)."

\section{DEVELOPING AUTOMATICITY IN LEARNING HANDICAPPED CHILDREN}

As stated, the key to making drill and practice an activity that will lead to automaticity in learning handicapped children is additional instruction for establishing a declarative knowledge network. Several instructional principles may be applied in establishing this network:

1. Determine learner's level of automaticity.

2. Build on existing declarative knowledge.

3 . Instruct on a small set of target facts.

4. Use controlled response times.

5. Intersperse automatized with targeted nonautomatized facts during instruction.

\section{Determine Learner's Level of Automaticity}

At any given point in time, most learning handicapped students recall some facts automatically; they answer others using counting strategies. To facilitate the automatic recall of all facts, instruction must be focused on nonautomatized facts while practice and review are given on facts that are already being recalled from memory. Thus identifying and separating automatized from nonautomatized facts is impor- tant.

We do this assessment using a computer program called CAMS - the Chronometric Assessment of Math Strategies (Hasselbring \& Goin, 1986). CAMS presents all 100 basic facts in an operation and records the amount of time that the child takes to answer each fact correctly. By measuring the latencies of student responses, we can accurately deter- mine the facts that are being recalled from memory and those that are solved using a counting strategy.

Following the assessment, CAMS constructs a Fast Facts matrix, as shown in Figure 3. Each cell in the matrix that is filled in represents a fact on which the student has automatized. The matrix allows us to visually see the facts that the student has automatized and the remaining facts that have to become automatized. The matrix indicates a common pattern in many learning handicapped students. This student has automatized most of the facts that include 0 and 1 as the minimum addend (e.g., $0+0$ to $0+9$, and $1+1$ to $1+8$, and the reversals). Also, he has automatized a few facts with 2 as a minimum addend, and some of the doubles (e.g., $3+3,4+4$, and $5+5$ ).

\section{Build on Existing Knowledge}

We expand the student's declarative knowledge network by building on existing knowledge. Consider the student whose matrix is shown in Figure 3. We could begin by working on $1+9$ and $9+1$, because he already has automatized all other facts with a minimum addend of 1 . As a general rule, we select facts to be automatized based upon the size of the minimum addend. For example, once all facts with a minimum addend of 1 have been automatized, we begin to select facts with a minimum addend of 2 , and so on, until all facts have been automatized.

\section{Instruct on a Small Set of Target Facts}

Our research suggests that it is best to work on developing declarative knowledge by focusing on a very small set of new target facts at any one time-no more than two facts and their reversals. Instruction on this target set continues until the student can retrieve the answers to the facts consistently and without using counting strategies.

\section{Use Controlled Response Times}

We begin to move children away from the use of counting strategies by using "controlled response times." A controlled response time is the amount of time allotted to retrieve and provide the answer to the fact. We normally begin with a controlled response time of 3 seconds or less and work down to a controlled response time around 1.25 seconds.

We believe that the use of controlled response times may be the most critical step to developing automatization. It forces the student to abandon the use of counting strategies and to retrieve answers rapidly from the declarative knowledge network.

If the controlled response time elapses before the child can respond, the student is given the answer and presented with the fact again. This continues until the child gives the 


\begin{tabular}{l|c|c|c|c|c|c|c|c|c|c|}
\multicolumn{2}{c}{0} & \multicolumn{1}{c}{1} & 2 & 3 & 4 & 5 & 6 & 7 & 8 & 9 \\
\cline { 2 - 10 } & $0+0$ & $0+1$ & $0+2$ & $0+3$ & $0+4$ & $0+5$ & $0+6$ & $0+7$ & $0+8$ & $0+9$ \\
\hline 1 & $1+0$ & $1+1$ & $1+2$ & $1+3$ & $1+4$ & $1+5$ & $1+6$ & $1+7$ & $1+8$ & $1+9$ \\
\hline 2 & $2+0$ & $2+1$ & $2+2$ & $2+3$ & $2+4$ & $2+5$ & $2+6$ & $2+7$ & $2+8$ & $2+9$ \\
\hline 3 & $3+0$ & $3+1$ & $3+2$ & $3+3$ & $3+4$ & $3+5$ & $3+6$ & $3+7$ & $3+8$ & $3+9$ \\
\hline 4 & $4+0$ & $4+1$ & $4+2$ & $4+3$ & $4+4$ & $4+5$ & $4+6$ & $4+7$ & $4+8$ & $4+9$ \\
\hline 5 & $5+0$ & $5+1$ & $5+2$ & $5+3$ & $5+4$ & $5+5$ & $5+6$ & $5+7$ & $5+8$ & $5+9$ \\
\hline 7 & $6+0$ & $6+1$ & $6+2$ & $6+3$ & $6+4$ & $6+5$ & $6+6$ & $6+7$ & $6+8$ & $6+9$ \\
\hline 7 & $7+0$ & $7+1$ & $7+2$ & $7+3$ & $7+4$ & $7+5$ & $7+6$ & $7+7$ & $7+8$ & $7+9$ \\
\hline 9 & $8+0$ & $8+1$ & $8+2$ & $8+3$ & $8+4$ & $8+5$ & $8+6$ & $8+7$ & $8+8$ & $8+9$ \\
\hline $9+0$ & $9+1$ & $9+2$ & $9+3$ & $9+4$ & $9+5$ & $9+6$ & $9+7$ & $9+8$ & $9+9$ \\
\hline
\end{tabular}

FIGURE 3

Fast Facts Matrix: An Example

correct answer within the controlled response time. If the answer to the fact is incorrect, the correct answer is provided and the fact is given again. We also expect answers to the known facts to be correct and retrieved within the controlled response time. If not, corrective feedback is provided.

\section{Intersperse Automatized and Target Facts}

Finally, our research suggests that it is best to work on developing a declarative knowledge network by interspersing the target facts with other already automatized facts in a prespecified, expanding order. Each time the target fact is presented, another automatized fact is added as a "spacer" so that the amount of time between presentations of the target fact is expanded. This expanding presentation model requires the student to retrieve the correct answers over longer and longer periods.

\section{EFFECTIVE USE OF DRILL AND PRACTICE}

Over several years of research, we have found that the principles described above, when implemented concurrently, are successful in establishing declarative knowledge networks in learning handicapped children. These principles are embodied in an experimental math program called Fast Facts (Hasselbring \& Goin, 1986), which successfully develops the recall of basic math facts in the four operations by removing a student's dependence on procedural strategies.

At first glance, Fast Facts appears to be a traditional drill and practice program, but, upon closer inspection, it is much more. Fast Facts individualizes instruction for each student based upon initial assessment of the student's level of automaticity. Further, controlled response times are adjusted based upon the student's level of success. Finally, the pro- 
gram carefully controls the student's movement from instruction to drill and practice.

As soon as a student is able to consistently retrieve the answer to a target fact within the controlled response time, that fact is added to the child's set of drill and practice facts. As stated previously, we believe that no fact should be practiced until a student is able to retrieve it from memory with ease.

The actual form of the computer-based drill and practice does not seem to be especially important as long as two criteria are met: (a) the student practices only facts that can be retrieved from memory, and (b) speed is emphasized during the drill and practice activity. Thus, the drill and practice program should be flexible enough to allow the teacher to select the facts to be practiced and the speed with which they are presented. Many drill and practice programs don't allow this flexibility and should be avoided because they encourage the student to use counting strategies to solve the nonautomatized facts.

\section{EFFECTS ON LEARNING HANDICAPPED CHILDREN}

We have found that the Fast Facts intervention is quite successful, even with learning handicapped children. In a recent study we examined a group of 160 mildly handicapped and nonhandicapped students ages 7 through 14 . The handicapped students were assigned to either a computer or contrast condition; the nonhandicapped students served as contrasts only.

The computer group received daily instruction using Fast Facts. Following each session on Fast Facts, the students received a brief period of computer-based drill and practice over the facts that the student could retrieve from memory. The combined retrieval training plus drill and practice averaged only 10 minutes per day. The two contrast groups received only the math instruction provided by their classroom teacher.

The results of the study are shown in Figure 4. On the pretest, the nonhandicapped students averaged 40 fluent

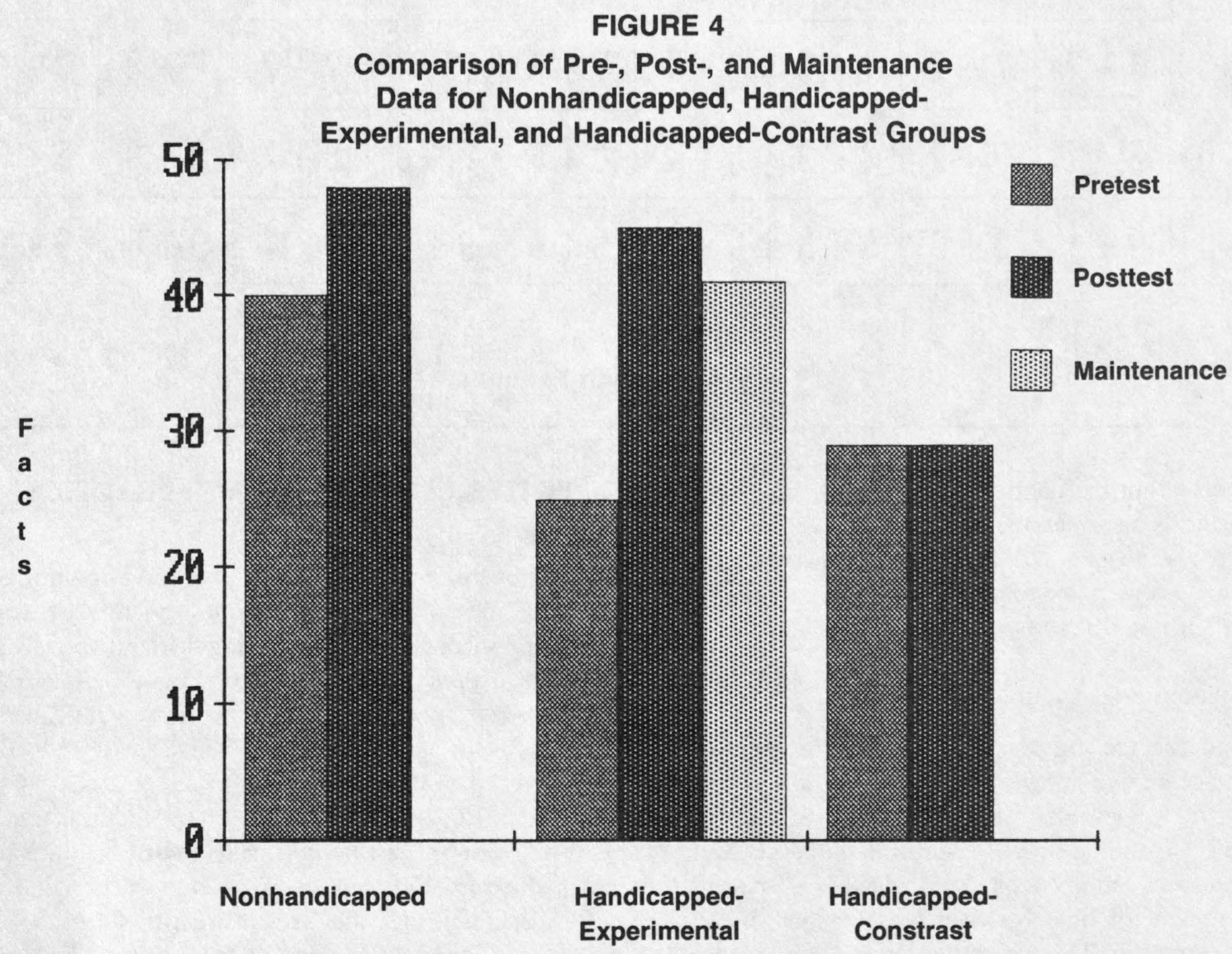


facts, while the handicapped-experimental and handicappedcontrast groups averaged 26 and 29 fluent facts respectively. After 49 days of using math software, the handicapped-experimental group increased the number of facts that were recalled from memory by $45-a 73 \%$ increase over the pretest. During the same period, the contrast group of handicapped learners showed no change on the number of facts that they could recall from memory, and the nonhandicapped contrast students averaged only 8 additional facts. Thus, the handicapped children developed fluent facts at a rate twice that of their nonhandicapped peers.

Maintenance data were collected on the handicapped-experimental group 4 months after the posttest. The posttest was conducted in May, and the maintenance test was conducted in October. We were interested in seeing how much regression would occur over the summer. As shown in Figure 4 , the group's average number of fluent facts dropped by only 4 facts.

From this research, we have concluded that the combination of recall training plus drill is a powerful mechanism for developing automaticity in handicapped learners. Further, with sufficient training, learning handicapped students should be able to develop automaticity at a level commensurate with their nonhandicapped peers.

\section{SUMMARY}

Most children with mild learning handicaps are deficient in basic math skills, and these deficits constitute a major obstacle to their overall success in mathematics. One of the most important reasons these children do poorly in math appears to be their failure to master the basic skills required to understand higher level math problems.

From our research and the research of others, neither paper and pencil drill and practice nor computer-based drill and practice seems to be sufficiently powerful in itself for developing automaticity in learning handicapped students. Additional work on developing a declarative knowledge network is needed before drill and practice is effective. Practice that allows students to use counting strategies for solving problems does nothing but strengthen students' use of counting strategies and does little to move the student toward a state of automaticity (Hasselbring, Goin, \& Sherwood, 1986).

In this article we have discussed procedures that can be used to develop automaticity in handicapped learners. In a recent test of these procedures, a number of handicapped children were able to attain a level of automaticity that was greater than that of their nonhandicapped peers. We believe that children with learning handicaps can attain automaticity at a level equal to their normal peers if care is taken to provide these children with appropriate instruction prior to placing them in drill and practice activities.

\section{REFERENCES}

Ashcraft, M. H. (1985). Children's knowledge of simple arithmetic: A developmental model and simulation. Unpublished manuscript, Cleveland State University.

Christensen, C. A., \& Gerber, M. M. (1986). Effects of game format in computerized drill and practice on development of automaticity in single digit addition for learning disabled students (Tech. Rep. No. 29). Santa Barbara: University of California, Project TEECh.

Fleischner, J. E., Garnett, K., \& Shepard, M. J. (1982). Proficiency in arithmetic basic facts computation of learning disabled children. Focus on Learning Problems in Mathematics, 4, 47-56.

Gagne, R. M. (1983). Some issues in the psychology of mathematics instruction. Journal for Research in Mathematics Education, 14(1), $7-18$.

Hasselbring, T. S., \& Goin, L. I. (1986). CAMS: Chronometic analysis of math strategies [Computer program]. Nashville, TN: Expert Systems Software.

Hasselbring, T. S., Goin, L. I., \& Bransford, J. D. (in preparation). Enhancing mathematical abilities in learning handicapped children.

Hasselbring, T. S., Goin, L. I., \& Sherwood, R. D. (1986). The effects of computer-based drill and practice on automaticity (Technical Report). Nashville, TN: Vanderbilt University, Learning Technology Center.

Hofmeister, A. (1983). Microcomputer applications in the classroom. New York: Holt, Rinehart \& Winston.

Howell, R. D., \& Graica, J. (1985, July). The effects of computer use on the generalization of learning with a learning disabled student. Paper presented at the Research Symposium on Special Education Technology, Washington, DC.

Lesgold, A. M. (1983). A rationale for computer-based reading instruction. In A. C. Wilkenson (Ed.), Classroom computers and cognitive science (pp. 167-181). New York: Academic Press.

Pellegrino, J. W., \& Goldman, S. R. (1987). Information processing and elementary mathematics. Journal of Learning Disabilities, 20(1), 23 32.

Resnick, L. B. (1983). A development theory of number understanding. In H. P. Ginsburg (Ed.), The development of mathematical thinking (pp. 109-151). New York: Academic Press.

Rieth, H. (1985, July). An analysis of the instructional and contextual variables that influence the efficacy of computer-based instruction for mildly handicapped secondary school students. Paper presented at the Research Symposium on Special Education Technology, Washington, DC.

Russell, R. L., \& Ginsburg, H. P. (1984). Cognitive analysis of children's mathematics difficulties. Cognition \& Instruction, I(2), 217-244.

Torgesen, J. K. (1984). Instructional uses of microcomputers with elementary aged mildly handicapped children. Special Services in the Schools, I(1), 37-48

This research was supported by Grant No. G008630134 from the Office of Special Education Programs in the Department of Education to Vanderbilt University. Points of view or opinions stated here do not necessarily represent official positions of Special Education Programs. 


\section{professional update}

\section{UPCOMING MEETINGS}

\section{February 24-27, 1988}

Association for Children and Adults with Learning Disabilities

International Conference

Las Vegas, Nevada

Contact: ACLD Inc.

4156 Library Road, Pittsburgh, PA 15234

(412) 341-1515

\section{March 28-April 1, 1988}

Council for Exceptional Children

Annual Convention

Washington, DC

Contact: Dept. of Professional Development, CEC

1920 Association Dr., Reston, VA 22091-1589

(703) 620-3660

\section{July 19-23, 1988}

Alexander Graham Bell Association for the Deaf

Biennial Convention

Orlando, FL

Contact: Susan Coffman

3417 Volta Pl. N.W.

Washington, DC 20007

(202) 337-5220 (voice/TDD)

\section{NEW BOOKS}

Children and Adolescents with Mental Illness

A Parents' Guide

Edited by Evelyn McElroy

Written by doctors, nurses, educators, and parents, this new paperback is edited by a professional who has also faced the problem of having a mentally ill child. The book includes frank, direct statements by parents about the impact of this illness on their marriages, families, and hopes for their children.

Supplementary material includes information about medications and their side-effects, a directory of relevant state organizations, evaluation form and checklist, glossary, and reading list: The publisher is Woodbine House, Kensington, MD.

\section{Directory of Residential Facilities For Emotionally Handicapped Children and Youth/Second Edition By Barbara Smiley Sherman}

Each of the approximately 1,000 entries in this revised and expanded edition describes a residential facility, its programs and services, data of staff, population served, funding sources, referral and application procedures. Placement guidelines are also included.

The publisher of this 285-page directory is Oryx Press, Phoenix, AZ. 